\title{
Emprego do GPR no Mapeamento de Tambores Plásticos Enterrados no SCGR do IAG
}

\author{
Selma Isabel Rodrigues ${ }^{1}$, Jorge Luís Porsani ${ }^{2}$, Welitom Rodrigues Borges ${ }^{1}$ \& Francisco Y. Hiodo ${ }^{2}$ \\ ${ }^{1}$ Pós-Graduação em Geofísica, IAG-USP. E-mail: selma@iag.usp.br; welitom@iag.usp.br \\ ${ }^{2}$ Departamento de Geofísica, Instituto de Astronomia, Geofísica e Ciências Atmosféricas, Universidade de São Paulo, Rua \\ do Matão, 1226, Cidade Universitária, São Paulo. E-mail: porsani@iag.usp.br
}

Copyright 2004, SBGf - Sociedade Brasileira de Geofísica

Este texto foi preparado para a apresentação no I Simpósio de Geofísica da Sociedade Brasileira de Geofísica, São Paulo, 26-28 de setembro de 2004. Seu conteúdo foi revisado pela Comissão Tecno-científica do I SR-SBGf mas não necessariamente representa a opinião da SBGf ou de seus associados. E proibida a reprodução total ou parcial deste material para propósitos comerciais sem prévia autorização da SBGt.

\section{Resumo}

No artigo são apresentados os resultados referentes à caracterização GPR de tambores plásticos instalados no Sítio Controlado de Geofísica Rasa do IAG-USP. A análise das reflexões permitiu distinguir os tambores vazios dos preenchidos com água fresca ou salgada, em diferentes profundidades. O padrão das reflexões de cada material, calibrados para alvos conhecidos, podem ser utilizados em áreas onde não há informações sobre a subsuperfície. Os resultados têm importantes aplicações em estudos de contaminação do meio ambiente.

\section{Introdução}

O desenvolvimento industrial proporciona qualidade de vida à população, em contrapartida, pode acarretar sérios impactos ambientais se não houver uma política de gerenciamento quanto à reutilização de áreas contaminadas por resíduos armazenados em tanques ou tambores dispostos na subsuperfície. Devido à falta de fiscalização, durante muito tempo, principalmente na região Metropolitana de São Paulo, esta situação contribuiu para que houvesse um aumento significativo de áreas potencialmente contaminadas (CETESB, 2001). Com base neste contexto, os tambores plásticos enterrados numa área de testes controlados, denominada de Sitio Controlado de Geofísica Rasa - SCGR do IAG, instalada no campus universitário da Universidade de São Paulo (Porsani, 2002), foram escolhidos pois podem simular contaminantes resistivos ou condutivos encontrados no contexto urbano.

A área onde foi instalado o Sítio Controlado de Geofísica Rasa-SCGR do IAG está situada na borda da Bacia Sedimentar de São Paulo, sendo constituída predominantemente por sedimentos areno-argilosos (formações Resende e São Paulo), sobrepostos ao embasamento granito-gnáissico (Borges, 2002; Porsani et al., 2004).
O mapeamento dos tambores plásticos através do método não-destrutivo GPR - Ground penetrating Radar faz parte do projeto de pesquisa de mestrado: "Caracterização GPR de tambores metálicos e plásticos: estudo sobre o sítio controlado do IAG-USP" (Rodrigues, 2004). As respostas GPR foram analisadas de forma integrada às simulações numéricas e as profundidades reais dos alvos, com o intuito de determinar a viabilidade do seu uso em aplicações relacionadas a estudos ambientais e obras de engenharia civil, num contexto urbano.

Neste artigo, serão apresentados os resultados obtidos com a aplicação do método GPR sobre a linha a qual foram enterrados os tambores plásticos. Os resultados proporcionaram informações significativas para a identificação e diferenciação dos tambores plásticos vazios dos preenchidos com água salgada ou doce, numa área de testes controlados.

\section{Metodologia}

O método GPR baseia-se na propagação de ondas eletromagnéticas (EMs) em altas freqüências (1 $\mathrm{MHz}$ a $2500 \mathrm{MHz}$ ). Uma antena transmissora dipolar disposta sobre a superfície, emite pulsos eletromagnéticos para dentro da Terra, ao encontrar mudanças nas propriedades físicas (elétricas e magnéticas) entre os materiais em subsuperfície, o sinal é refletido e registrado em tempo duplo (tempo de ida e volta) por outra antena receptora, também disposta na superfície. As ondas refletidas recebidas pela antena receptora são convertidas em sinais elétricos e transmitidas para a unidade de controle (Davis \& Annan, 1989; Daniels, 1996; Conyers \& Goodman, 1997).

A aquisição de dados foi realizada "antes" e "depois" da instalação dos alvos no SCGR-IAG, utilizando as antenas de $100 \mathrm{MHz}, 200 \mathrm{MHz}$ e $500 \mathrm{MHz}$. Estas duas etapas de aquisições são fundamentais, pois fornece informações sobre a composição geológica e as interferências relacionadas aos alvos enterrados, respectivamente. Neste artigo, serão apresentados apenas os resultados obtidos com as antenas de $200 \mathrm{MHz}$, através dos modos passo-a-passo (Figura 1) e contínuo (Figura 2). Para as aquisições no modo passo-a-passo, foi utilizado incrementos espaciais $(\Delta \mathrm{x})$ de $0.2 \mathrm{~m}$ e empilhamento 
(stack) de 256; e no modo contínuo, $\Delta x=0.05 \mathrm{~m}$ e stack de 32 .

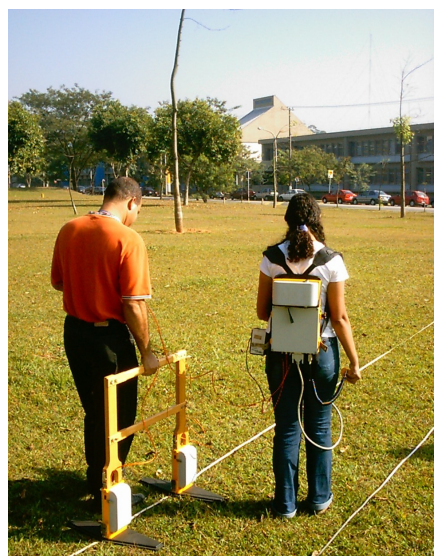

Figura 1. Aquisição de dados GPR com as antenas de $200 \mathrm{MHz}$, modo passo-a-passo.

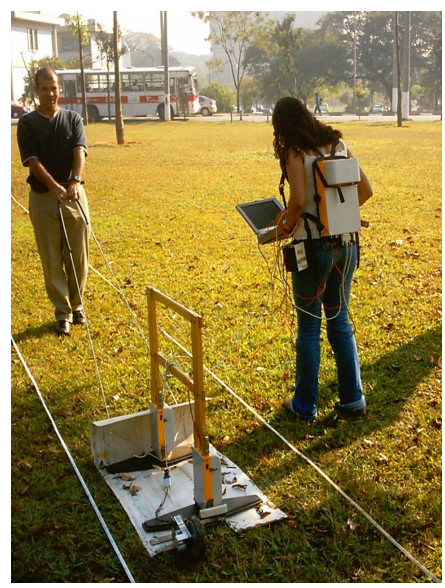

Figura 2. Aquisição de dados GPR com as antenas de $200 \mathrm{MHz}$, modo contínuo.

Além do método GPR, estão sendo utilizados os métodos da eletrorresistividade, polarização induzida, eletromagnético indutivo (EM-38) e magnetometria para caracterizar o SCGR do IAG (Borges, 2004). Alguns resultados preliminares são apresentados por Porsani et al. (2004) e Borges et al. (2004).

O SCGR do IAG é constituído por sete linhas, em cada linha foram enterrados alvos específicos simulando várias situações encontradas no contexto urbano. Os tambores plásticos foram dispostos sobre a Linha 4 em diferentes profundidades, sendo que alguns estavam vazios e outros, preenchidos com água salgada ou água fresca (Figura 3).

As trincheiras para a instalação dos alvos no SCGR-IAG, foram abertas utilizando uma retroescavadeira, e os alvos foram dispostos nas posições e profundidades préestabelecidas com o auxílio de trenas e uma Estação Total, o qual permitiu obter valores precisos quanto o posicionamento e a altitude dos alvos.

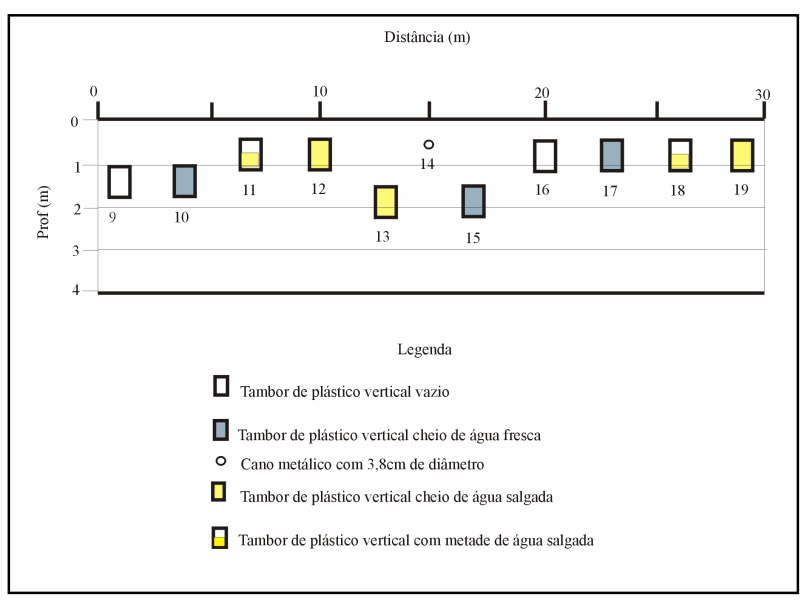

Figura 3. Disposição espacial dos tambores de plásticos.

\section{Discussão dos Resultados}

Na Figura 4 são apresentados os perfis GPR adquiridos com as antenas de $200 \mathrm{MHz}$. A conversão do tempo em profundidade foi realizada através do ajuste de velocidade dos refletores hiperbólicos.

$\mathrm{Na}$ Figura 4a pode ser observada a composição geológica da área anterior à instalação dos alvos em subsuperfície, i.e., o background. A atenuação do sinal aproximadamente a $1 \mathrm{~m}$ e $1.5 \mathrm{~m}$ de profundidade deve-se a presença de materiais altamente condutores provenientes do aterro sobreposto aos sedimentos da Bacia de São Paulo (Borges, 2002; Porsani et al., 2004).

$\mathrm{Na}$ Figura 4b e 4c são mostrados os resultados GPR através do modo passo-a-passo e contínuo, respectivamente. Os dados GPR adquiridos através do modo passo-a-passo apresentaram uma melhor relação sinal/ruído, tornando mais intenso o sinal dos refletores correspondentes aos alvos profundos, visto que para este tipo de aquisição utiliza-se um maior empilhamento dos traços. Por outro lado, o modo contínuo, proporcionou uma melhor resolução espacial em virtude da diminuição do incremento espacial, de $0.2 \mathrm{~m}$ para $0.05 \mathrm{~m}$, além de otimizar o tempo de aquisição dos dados. Observa-se que os resultados se complementam. Este fato pode ser comprovado através da análise dos refletores hiperbólicos mais profundos correspondente aos alvos instalados a $2 \mathrm{~m}$ de profundidade (Figuras $4 \mathrm{~b}$ e $4 \mathrm{c}$ ).

Verifica-se que todos os tambores plásticos e o cano metálico (utilizado como um alvo guia) foram identificados através das reflexões hiperbólicas geradas no topo e/ou na base dos tambores. 
Os tambores vazios, semipreenchidos com água salgada, cheios de água salgada e o cano metálico foram caracterizados por refletores gerados no topo (interface solo argiloso/topo do alvo). As bases dos tambores vazios e semipreenchidos com água salgada não foram identificadas devido a elevada velocidade de propagação da onda eletromagnética no ar, sendo maior que a do solo argiloso, proporcionando uma sobreposição do $1^{\circ}$ refletor (topo) com o $2^{\circ}$ refletor (base); e a base dos tambores cheios de água salgada não foi caracterizada em virtude da elevada atenuação da onda eletromagnética.

Em contrapartida, os tambores cheios de água fresca, foram caracterizados através dos refletores gerados na base (interface base do tambor/solo argiloso); no topo destes tambores são produzidas reflexões de baixa amplitude, fato associado à baixa impedância elétrica na interface e a atenuação do sinal, ou seja, a condutividade elétrica do background é maior que a da água fresca. Nota-se que a intensidade dos refletores está relacionada à profundidade em que se encontram os alvos; os mais profundos, dispostos em $1.5 \mathrm{~m}$, foram caracterizados por fracos refletores, e os mais rasos, dispostos a $0.5 \mathrm{~m}$, foram caracterizados por fortes reflexões.

\section{Conclusões}

A utilização do método GPR proporcionou uma caracterização qualitativa dos tambores plásticos enterrados no SCGR - IAG, os quais simulam situações reais encontradas no contexto urbano. Através do padrão das reflexões foi possível discriminar os tambores plásticos nas diferentes profundidades, bem como os seus preenchimentos. Os tambores mais rasos foram melhores caracterizados se comparados aos mais profundos, em virtude da atenuação do sinal eletromagnético provocada pela presença de materiais condutivos provenientes do aterro. Os resultados obtidos sob condições controladas de campo servem como respostas padrões e poderão ser extrapolados para áreas onde não há informações sobre a subsuperfície, auxiliando nos estudos de contaminação ambiental.

\section{Agradecimentos}

Ao Depto. de Geofísica do IAG-USP. A CAPES pela bolsa de pesquisa de mestrado. À FAPESP pelo auxilio financeiro para a instalação do SCGR (02/07509-1) e pela bolsa de doutorado do Welitom (02/07510-0). Ao Professor Francisco Hiodo, pelo desenvolvimento do "trenó" do GPR, utilizado na aquisição de dados para rebocar as antenas não blindadas. Ao técnico Ernande Costa Santos e a aluna de mestrado Elizete Maria Araújo da Silva, pelo auxílio na instalação dos alvos e na aquisição dos dados GPR.

\section{Referências}

Borges, W.R., 2002. Investigações geofisicas na borda da Bacia Sedimentar de São Paulo, utilizando-se GPR e Eletrorresistividade. Dissertação de Mestrado, IAG/USP. São Paulo, 153p.

Borges, W.R., 2004. Caracterização geofísica de alvos rasos com aplicações no planejamento urbano e meio ambiente: Estudo sobre o sítio controlado do IAG/USP. Tese de Doutorado, IAG-USP, São Paulo - SP (em desenvolvimento).

Borges, W.R., Porsani, J.L.; Silva, E.M.A \& Elis, V.R., Hiodo, F., 2004. Utilização de tomografia elétrica na identificação da interface entre uma cobertura antrópica e sedimentos fluviais na área do Sítio Controlado de Geofísica Rasa do IAG/USP. Anais do I Simpósio de Geofísica da SBGf, São Paulo.

CETESB - Companhia de Tecnologia de Saneamento Ambiental, 2001. Manual de gerenciamento de áreas contaminadas, 2 ed., São Paulo, 389p. Disponível em ihttp://wwww.cetesb.sp.gov.br/Sololo/areas contaminadas/mi anual.asp.

Conyers, L.B. \& Goodman, D., 1997. Ground penetrating radar: an introduction for archaeologists. Altamira Press A Division of Rowman \& Littlefield Publishers, Inc. Oxford, Englad, 232p.

Daniels, D.J., 1996. Surface penetrating radar. The Institution of Eletrical Engineers, London, United Kingdom, 300p.

Davis, J.L. \& Annan, A. P., 1989. Ground penetrating radar for high resolution mapping of soil and rodk stratigraphy. Geophysical, v.37, pp. 531-551.

Porsani, J.L., 2002. Caracterização geofísica de alvos rasos com aplicações no planejamento urbano, meio ambiente e arqueologia: estudo sobre o Sítio Controlado do IAG/USP. Projeto de Pesquisa. Processo FAPESP No. 02/07509-1, São Paulo - SP.

Porsani, J.L.; Borges, W.R.; Elis, V.R.; Diogo, L.A.; Hiodo, F.Y.; Marrano, A. \& Birelli, C.A., 2004. Investigações geofísicas de superfície e de poço no sítio controlado de geofísica rasa do IAG-USP. Revista Brasileira de Geofísica (no Prelo)

Porsani, J.L.; Rodrigues, S.I. \& Borges, W.R., 2004. O Sítio Controlado de Geofísica Rasa do IAG-USP: Instalação e Resultados Preliminares. Anais do I Simpósio de Geofísica da SBGf, São Paulo.

Rodrigues, S.I., 2004. Caracterização GPR de tambores metálicos e plásticos: estudo sobre o sitio controlado do IAG-USP. Dissertação de Mestrado, IAG/USP. São Paulo. 
a)

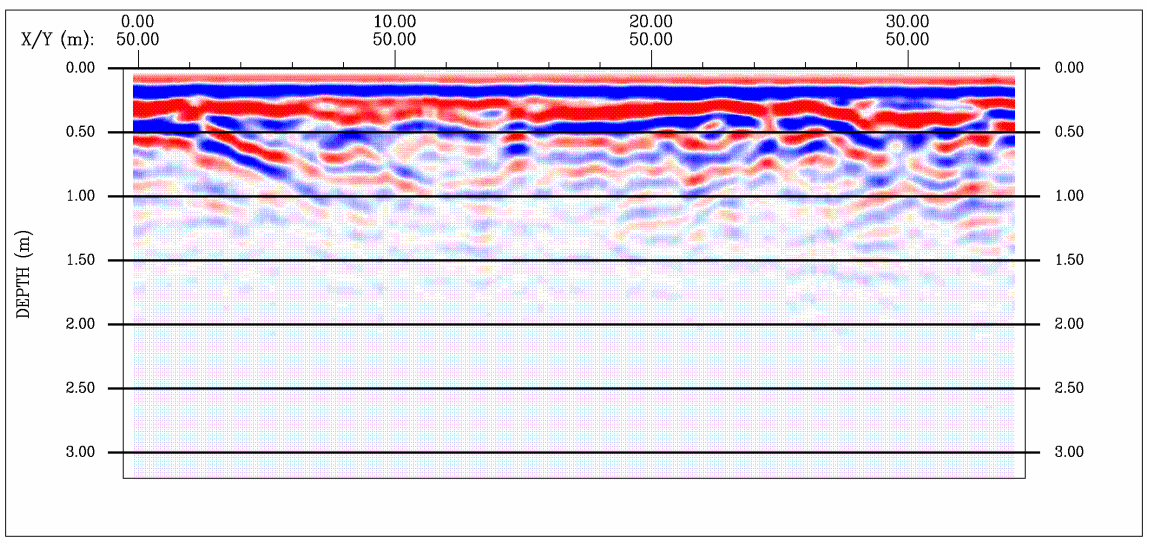

b)

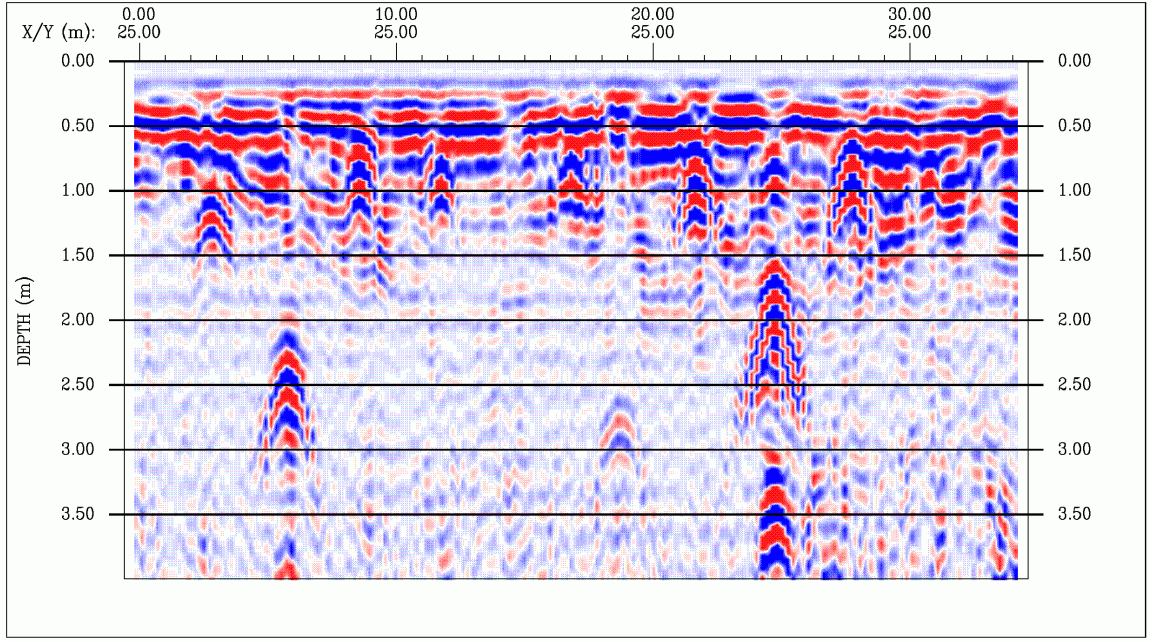

c)

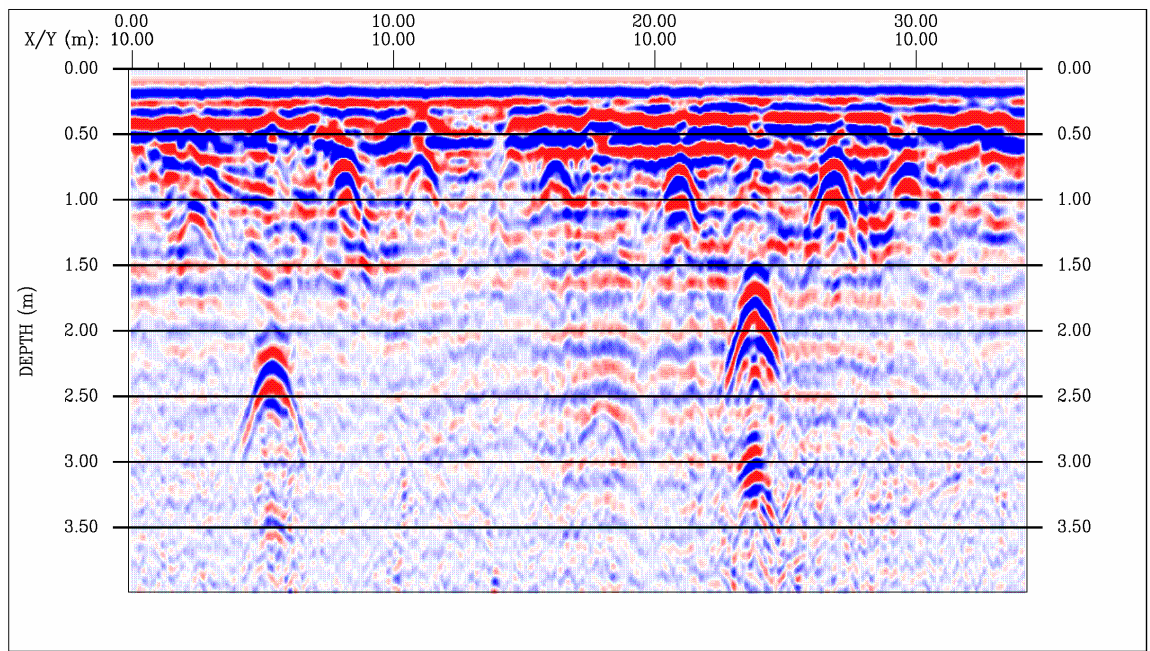

Figura 4. Perfis GPR adquiridos com as antenas de $200 \mathrm{MHz}$ sobre a linha dos tambores plásticos: a) "antes" da instalação dos alvos, modo passo-a-passo, b) "depois" da instalação dos alvos, modo passo-a-passo e c) "depois" da instalação dos alvos, modo contínuo. 